\title{
Total phallic construction techniques in transgender men: an updated narrative review
}

\author{
Marco Falcone ${ }^{1,2}$, Mirko Preto ${ }^{2}$, Gideon Blecher ${ }^{3,4}$, Massimiliano Timpano ${ }^{2}$, Paolo Gontero ${ }^{2}$ \\ ${ }^{1}$ Department of Neurourology, A.O.U. Città della Salute e della Scienza di Torino - Unità Spinale Unipolare, Turin, Italy; ${ }^{2}$ Department of Urology, \\ A.O.U. Città della Salute e della Scienza di Torino - Molinette Hospital, Turin, Italy; ${ }^{3}$ Department of Urology, The Alfred Hospital, Melbourne, \\ Australia; ${ }^{4}$ Monash Health, Bentleigh East, Australia \\ Contributions: (I) Conception and design: M Falcone, M Preto; (II) Administrative support: P Gontero; (III) Provision of study materials or patients: \\ M Timpano, M Falcone; (IV) Collection and assembly of data: M Preto, G Blecher; (V) Data analysis and interpretation: G Blecher, M Falcone, M \\ Preto; (VI) Manuscript writing: All authors; (VII) Final approval of manuscript: All authors. \\ Correspondence to: Mirko Preto, MD. Department of Urology, "Città della Salute e della Scienza" - Molinette Hospital, Department of Surgical \\ Sciences, University of Turin, Turin, Italy. Email: mirko.preto@unito.it.
}

\begin{abstract}
From 2012, the World Professional Association Transgender Health defined a structured therapeutic path and standards of care for transgender patients undergoing genital gender affirming surgery (GGAS). The main goal of GGAS in transgender males is to provide patients with an aesthetically appealing appearance of the neophallus that should allow standing micturition and enabling penetrative intercourse along with erogenous and tactile sensitivity. The optimal procedure should be safe, reproducible and performed in the fewest number of surgical stages. The ideal technique for total phallic construction (TPC) has not yet been demonstrated; TPC remains challenging and, from a functional point of view, it is also make more demanding as yet there are no perfect replacement materials for erectile and urethral tissues. Several procedures and different type of flaps (pedicled and free-flaps) have been proposed and investigated over time to address TPC with significant advances over the years especially after microsurgical procedures introduction. Due to its high complexity TPC is not free from complications. Local tissue ischaemic complications, complete and partial flap loss, donor site morbidity and urethral complications (fistulae and strictures) are reported. This narrative review aims to provide the readers with a contemporary overview of surgical procedures for TPC in transgender males focusing on key surgical steps, as well as surgical and functional outcomes.
\end{abstract}

Keywords: Phalloplasty; transgender men; total phallic construction (TPC)

Submitted Oct 14, 2020. Accepted for publication Feb 25, 2021.

doi: $10.21037 /$ tau-20-1340

View this article at: http://dx.doi.org/10.21037/tau-20-1340

\section{Introduction}

In 2012 the World Professional Association Transgender Health (WPATH) highlighted the standards of care and defined the structured therapeutic paths for transgender patients requiring genital gender affirming surgery (GGAS) (1).

The main goal of GGAS in transgender males is to provide patients with an aesthetic neophallus that should allow standing micturition and enabling penetrative intercourse along with erogenous and tactile sensitivity
(2-8). These qualities should be attainable using both safe and reproducible techniques, performed in the fewest number of surgical stages. The ideal technique for total phallic construction (TPC) has not yet been demonstrated; neophallus formation remains complicated as yet there are no perfect replacement materials for erectile and urethral tissues (9-15). Several procedures and different type of flaps have been proposed and investigated over time to address TPC, each with their inherent pros and cons. Whilst a shared consensus about the ideal reconstructive technique is 


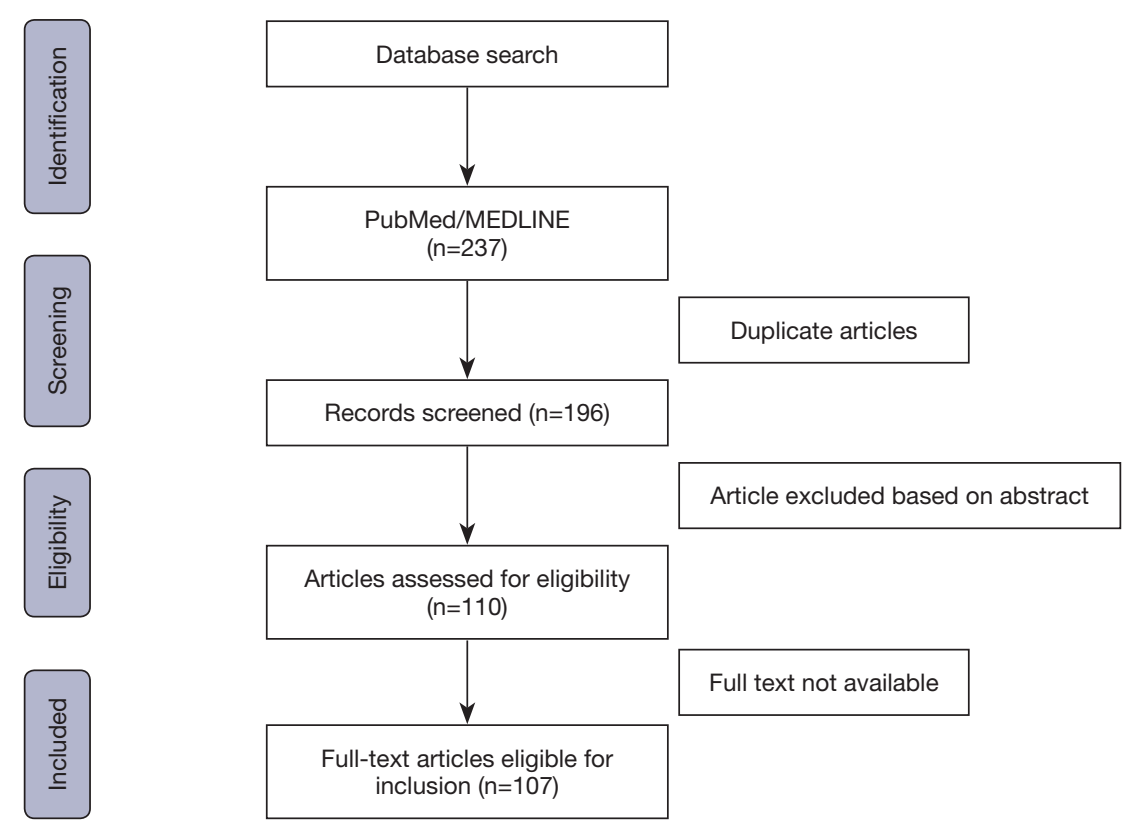

Figure 1 Selec+on process of the systema+c review according to STROBE check-list.

still lacking $(16,17)$ This systematic review aims to provide the readers with a contemporary overview of surgical procedures for TPC in transgender males. We present the following article in accordance with the PRISMA checklist (available at: http://dx.doi.org/10.21037/tau-20-1340).

\section{Methods}

\section{Study characteristics and acquisition of evidence}

The review was conducted in accordance with the PRISMA declaration standards for systematic reviews (18). A systematic search for the MeSH terms "phalloplasty", "transgender men", "neophallus", "genital gender affirming surgery" was carried out in PubMed, EMBASE, Cochrane, SCOPUS and Science Citation Index databases. No time-related limits were applied. Phalloplasty techniques considered in the present review included the radial artery forearm free flap (RAFFF), abdominal suprapubic pedicled flap (SPP), anterolateral thigh flap (ALT), latissimus dorsi flap (LDF), fibular osteocutaneous flap (FOFF) and the local groin flap (GF).

All available series discussing results of the aforementioned techniques in transgender men were included. Review papers, commentaries, editorials, letters, case-reports, non-English papers, studies on animal, genetic males or cadavers were excluded. Research results were screened by titles, abstracts and full texts by two reviewers (MP and MF) independently. Disagreement between the reviewers was resolved by discussion and consensus involving a third investigator (MT). Data analysis was conducted for each specific technique considering outcomes, complication and patient satisfaction rates.

\section{Results}

The selection process is summarised in Figure 1. The initial literature search retrieved a total of 237 potentially relevant articles. A total of 127 articles were excluded due to unmet inclusion criteria. A total of 107 articles were ultimately included in the present review. More than 750 transgender men whom underwent phalloplasty were included.

For each technique the current evidence on the key surgical steps, as well as surgical and functional outcomes were included.

\section{Radial forearm free flap (RAFFF)}

Despite the lack of well-structured comparative studies supporting the superiority of RAFFF over others flaps, RAFFF phalloplasty is currently considered as the gold standard techniques for TPC by most reconstructive surgeons $(2,4,8,9,14,16,19-25)$.

Chang and Hwang described the first RAFFF phalloplasty in 1984 (26). In 1993 their technique was 
modified by Gottlieb and Levine. The design of the flap was slightly modified, placing the neourethra over the course of the radial artery in order to reduce the risk of ischaemic urethral complications (27). Both techniques apply the "tube-within-tube" principle with which the construction of the neourethra and neophallus is performed in a single stage procedure $(9,26,27)$.

RAFFF is supplied by the radial artery and drained by several veins (cephalic, basilic, venae comitantes and lateral flap veins). Flap sensation is supplied by the medial and lateral cutaneous nerve of the forearm.

RAFFF possesses some advantages including thin and pliable skin, a long vascular pedicle with good caliber blood vessels. The main drawback of RAFFF is its donorsite morbidity because nearly two-thirds of the forearm circumference is harvested. This area requires coverage with either full or split-thickness skin grafts, which may create sizeable scarring $(9,26,28)$. Other disadvantages include discolouration between the flap and surrounding genital skin $(3,29)$, need for a stiffener or prosthesis to allow penetrative intercourse and relatively high rate of urethral complications $(2,14,16,24,29)$.

\section{Surgical steps}

Although various configurations are possible, our preferred approach for RAFFF phalloplasty is completion in three stages as follows:

(I) Flap harvesting and transfer;

(II) Glans sculpture, vaginectomy, urethral anastomosis and scrotoplasty;

(III) Penile prosthesis implantation (PPI).

\section{Step 1-Flap harvesting and transfer}

Usually, the non-dominant forearm is selected as the donorsite. A preoperative Allen test or a duplex ultrasonography (when Allen test is in doubt) are mandatory to confirm the ulnar artery patency (30).

RAFFF is generally composed of a medial strip to form the neourethra plus a lateral paddle that is rolled around the neourethra to form the neophallus, following the "tube within a tube" principle. The medial strip is tubularised over a $16-\mathrm{F}$ catheter to create the neourethra. The radial artery is dissected carefully up to its origin from the brachial artery. Interosseus and ulnar branches are spared. The flap remains attached until the recipient vessels are prepared. A microsurgical anastomosis is subsequently performed. The radial artery is anastomosed with the deep branch of the inferior epigastric artery in an end-to-end fashion or with the femoral artery in an end-to-side configuration. The cephalic vein is anastomosed with the great saphenous vein (end-to-end), while accessory flap veins (basilic or lateral flap) are joined either to the accessory saphenous vein or to the venae comitantes of the epigastric artery. The cutaneous nerves of the flap are coapted to one of the ilioinguinal nerves to provide tactile sensation and to one of the dorsal clitoral nerves to ensure erogenous sensation $(31,32)$.

To provide sufficient rigidity for the phallus, a modified technique incorporated a portion of radial bone (radial forearm osteocutaneous flap) and was proposed by Kim et al. $(17,19)$. However, issues involving bone resorption became apparent over time. This approach has subsequently gone out of favour with many surgeons.

\section{Step 2-Glans sculpture, vaginectomy, urethral anastomosis and scrotoplasty}

To provide a more realistic cosmetic aspect to the phallus, glans sculpture is performed creating a pseudo-corona of the glans. The Norfolk technique and its modifications are the most frequently applied $(12,14,33,34)$. A full-thickness skin graft is harvested from the supero-anterior iliac spine and used to create the coronal sulcus.

The anastomosis between the neourethra and the native urethra (pars fixa) can be performed either during the first surgical stage or in this second stage (which is currently our preferred option). In both cases, an end to end anastomosis is performed using a combination of local labial flaps and a rotated anterior-wall vaginal flap over a 16 French stent. A Martius' fat pad is mobilised over the urethral anastomosis to minimize fistula formation. The clitoris is de-epithelised, mobilised and hidden at the base of the neophallus $(35,36)$. An ablation vaginectomy with simultaneous scrotoplasty is be performed suturing the labia majora along the midline $(37,38)$.

\section{Step 3-Penile prosthesis implantation (PPI)}

The last stage is the insertion of a penile implant to provide the necessary rigidity for penetrative intercourse.

\section{Outcomes}

Due to its high complexity RAFFF phalloplasty is not free from complications. Local tissue ischaemic complications in free-flaps TPC may range from $5 \%$ to $11 \%(1,24,27)$. Complete flap loss and partial flap loss or distal necrosis after RAFFF range from $1.5-5 \%$ and $5.4-11 \%$ respectively 
$(24,37,39,40)$. The revision rate of microvascular anastomosis is not to be neglected; Doornaert et al. reported a need for revision in $11 \%$ of RAFFF flaps (16). De Wolf et al. have recently proposed a technique involving the posterior interosseous artery to supercharge RAFFF blood supply. This new described procedure seems to enhance RAFFF perfusion and to minimize marginal necrosis (41).

Donor site morbidity includes graft failure requiring re-grafting in $2.7 \%$ of cases $(9,25,28,42)$. Urethral complications are the most frequently reported complication, ranging from $32 \%$ to $58 \%(36,38,43)$. Urethrocutaneous fistula formation and urethral strictures occur in up to $26-30 \%$ and $8-12 \%$ respectively. These require urethral revision surgery in $17 \%$ of cases $(22,37,38)$.

RAFFF phalloplasty outcomes are generally satisfactory. $87 \%$ of patients report neophallus sensation and approximately $80 \%$ achieve orgasm. Satisfaction rates for cosmetic appearance have been described up to $97 \%$ $(6,9,17,44)$. Most $(75-100 \%)$ of patients can void in the standing position $(22,24,26,36,45,46)$.

\section{Abdominal flap-SPP}

The abdominal region is a suitable donor site for many pedicled flaps to apply in genital reconstructive surgery. A large amount of pliable skin flaps could be harvested and the donor site could be closed primarily or with the assistance of local rotational flaps. Donor-site scar is often easily concealed by clothing and underwear. Some authors suggested that SPP could be considered as a valid alternative to a free-flap TPC in case of active smokers or when the $\mathrm{BMI}$ is over 30 , in order to reduce the risk of wound and vascular complications (47).

The first abdominal flap description for TPC, in 1936, was made by Bogoras (48), who reported the use of a random pedicled abdominal flap with incorporated rib cartilage. From his first experience, several authors have published refinements of his approach in GGAS setting.

Maltz and Gillies/Harrisson improved Bogoras' technique by incorporating a neourethra into the phallus $(49,50)$. Initially most abdominal flaps were based on the deep inferior epigastric perforator artery (DIEP) $(38,51,52)$. Despite being described, surgical and functional outcomes related to these techniques are unfortunately lacking in the literature. There are several limitations of these techniques including the need for multiple procedures, extensive donor site scarring as well as a wedge-shaped and non-sensate neophallus.
More recently a further modification of the abdominal flap, the suprapubic pedicled phalloplasty (SPP) was reported by Bettocchi et al. (53).

\section{Surgical steps}

Different techniques can be considered to fashion a SPP. The original description (53) and a recent modification by Falcone et al. (47) were based on a single stage procedure. Falcone's version involved harvesting a flap from the anterior abdominal wall starting from the base of the clitoris. A rectangular shaped skin area (on average $12 \mathrm{~cm}$ wide and $13 \mathrm{~cm}$ long) with a rounded end is marked. If possible, the superficial external pudendal vessels should be included into the flap pedicle. Once the flap is mobilised up to the underlying muscle fascia, redundant subcutaneous tissue is trimmed, if necessary ( $79 \%$ of cases), to improve final cosmesis and to reduce tension once the flap is tubularized (47). The abdominal defect can be closed primarily or by the use of two rotational pedicled flaps to minimize wound tension (70\%) (47).

Urethral reconstruction can occur within the SPP in a separate stage. Initially total length urethroplasty was attempted, utilising genital or abdominal skin flaps. However, these approaches incurred a high incidence of complications such as fistulas (from $22 \%$ up to $55 \%$ ) and strictures (from $27 \%$ up to $64 \%$ ) $(3,45,47,54,55)$ and were therefore abandoned.

Garaffa $e t a l$. described a second stage radial artery based urethroplasty (RAU) whereby a neo-urethra is incorporated into the SPP. Despite some donor-site morbidity, RAU affords lower urethral complications (stricture and fistula up to $12 \%)(45)$.

Terrier et al. described the use of an abdominal tissue expander, dividing the operation into three separate stages, aiming to reduce the risk of ischaemic complications (54).

Glans sculpting, join-up urethroplasty, vaginectomy and scrotoplasty follow the previously described steps for RAFFF.

\section{Outcomes}

SPP postoperative complications include wound infection (9.9-40\%), shearing sutures $(5.8-69.2 \%)$, need for regrafting $(7.4 \%)(3,37,52,53)$, distal flap necrosis $(3.8-$ $5.8 \%)(54,55)$, need for surgical revision $[8.7 \%(54), 29 \%$ (52)] and uncommonly complete flap loss (3.5\%) (47).

Distal flap ischaemia can be managed by segmental 
amputation, often preserving an acceptable residual length of the neo-phallus (47).

Whilst penile implants have their own list of complications, occasionally [up to $19.6 \%$ of cases $(3,47)$ ] SPP may result in sufficient rigidity for penetrative sexual intercourse without the need for implant surgery.

SPP satisfaction rates are quite acceptable compared to other phalloplasty series, with $57 \%$ to $95 \%$ of patients describing overall satisfaction $(3,47,53,54)$ with their choice. Eighty-three percent report satisfaction with the final appearance of the phallus and $89 \%$ would recommend or undergo the same procedure again (53). Functional outcomes are also quite satisfactory: $79 \%$ of patients reported to have a satisfying sexual life and 55-66\% reported being able to reach orgasm $(53,54)$.

\section{ALT flap}

An alternative to the popular RAFFF is the ALT flap phalloplasty. ALT was initially described in 1965 as a free flap, while later an ALT pedicled flap was reported as a single step procedure $(40,56)$. The latter is attractive due to the lack of requirement for microsurgical techniques and for reduced operative times $(3,40,56,57)$.

ALT advantages include:

* smaller, less exposed and more discreet donor site scar, easily concealable with clothes;

* reduced risk of total flap failure (when pedicled);

* skin color match of the phallus with genital area;

- absence of any sacrifice of a major vascular pedicle $(39,40,57,58)$.

On the other hand the main drawbacks of pedicled ALT flap are:

* although concealable, a significant donor site defect exists which require skin grafting;

* inability to create single stage incorporated urethra if the skin thickness $>1 \mathrm{~cm}(7,40)$, with subsequent requirement for combination flap phalloplasty (41);

* comparatively low sensation, relying on a single cutaneous nerve.

ALT flap blood supply relies on the cutaneous perforators of the descending branch of the lateral circumflex femoral artery (LCFA) and the flap is innervated by the lateral femoral cutaneous nerve (40). The high anatomical variability in ALT flap perforators vessels was considered an issue by many authors but recent evidence has demonstrated otherwise $(3,57)$. In a large series, Wei reported the absence of suitable perforator vessels in less than $1 \%$ of cases $(57,59)$.
During the preoperative evaluation, van der Sluis et al. demonstrated that CT angiography and Doppler ultrasound can facilitate perforator vessel selection based on the patient's anatomical features (39). One perforator vessel, adequate in diameter, has generally proved to suffice for the perfusion of a large skin paddle, so partial and total flap losses have been recorded less frequently than after $\operatorname{RAFFF}(7,39,40)$.

ALT flap erogenous sensation is provided by the inclusion of the lateral femoral cutaneous nerve (56). This nerve is coapted to the ilioinguinal and dorsal nerves of the clitoris providing tactile and erogenous sensitivity of the flap. Tactile sensation usually is established after 6 months from TPC $(7,40)$.

\section{Surgical steps and outcomes}

Preoperatively, perforator vessels from the descending branch of the LCFA are identified and marked on the skin with a doppler probe and/or CT angiography. The anterosuperior iliac spine and the lateral border of the patella are linked with a line corresponding to the intermuscular septum between rectus femoris and vastus lateralis. The septum is just medial to the perforator vessels. The ALT flap has a rectangular shape of $10-12$ or $11-14 \mathrm{~cm}$ and it is marked on the side with the preferred vascular supply.

The surgical incision is performed $3 \mathrm{~cm}$ anteriorly to the septum on the medial edge of the donor area. The anatomical dissection is performed subfascially to identify the perforator vessels. Once the major perforator vessel is located, the dissection of the vascular pedicle is performed through the muscle or the septum to reach the descending branch of the LCFA. Motor branches of the femoral nerve should be separated while the lateral femoral cutaneous nerve is included in the flap. At the end of the pedicle dissection, the identified flap is incised and harvested suprafascially, leaving only a small amount of protective fascia around the perforator pedicle. A V or $\mathrm{W}$ shaped skin incision is made on the pubis and the flap is passed under the rectus femoris and sartorius muscles. The flap is thus transposed to the genital area. The flap is tubularised and minor adjustments are required depending on the flap thickness and need for simultaneous urethral reconstruction. It the flap is too thick for a tension-free primary closure, it can be thinned to avoid venous congestion during tubularisation. The donor site area is reduced by primary closure where possible and then a STSG, harvested from the contralateral thigh, is applied to the resulting defect.

The flap end of the lateral femoral cutaneous nerve is 
coapted with the ileo-pubic, ilioinguinal nerves or with the dorsal nerves of the clitoris. Subsequently a glans sculpture and join-up urethroplasty are simultaneously performed. In 2014, Morrison et al. described the Mushroom flap technique, with a semicircular extension at the distal portion of the flap to incorporate a glans structure. The final surgical step again involves PPI $(12,14,56,60)$.

ALT flap can be performed with either concomitant or delayed urethral reconstruction.

Different techniques have been described (61):

* ALT tubularised with a "the tube within a tube" technique $(40,62)$;

* ALT flap combined with a skin graft or periclitoral hairless cutaneous flap (57);

* $\quad$ ALT flap combined with RAFFF $(39,40)$;

* ALT flap combined with a pedicled superficial circumflex iliac artery perforator flap.

The tube within a tube technique is recommended only for patients with a thin layer of subcutaneous fat in the flap, ideally less than $1.5 \mathrm{~cm}$. Thicker tissues can cause difficulties with rolling the tube twice in a single stage procedure. Some authors therefore prefer a two stage procedure with an interval time period of 6-8 months $(40,62)$.

Published data of ALT phalloplasty outcomes are limited, but encouraging. The ability to micturate in standing position has been reported in more than $65 \%$ of cases, penetrative intercourse in $60 \%$ and a high grade (up to $100 \%$ ) of satisfaction with the aesthetic appearance of the phallus were recorded $(3,37)$.

Some authors have compared ALT and RAFFF complication rates. The results of these series were in contrast as Fischer demonstrated that patients undergoing RAFFF experienced greater complications than ALT free flap in terms of donor-site complications ( $35 \%$ vs. $12 \%$ ) and wound dehiscence $(30 \%$ vs. $5 \%)$. While Ascha et al. reported a higher rate of urethral fistula (22\%vs. 10\%) and flap dehiscence $(9.5 \%$ vs. $2 \%)$ after the pedicled ALT flap compared with RAFFF (43). The authors suggested that the thicker amount of subdermal fat in the thigh leads to increased tissue ischaemia, explaining the variance in results. Pedicled ALT defatting could reduce flap thickness and make easier neophallus tubularisation but it increases the risk of vascular complications such as partial flap loss $(43,62)$.

Urethral-related complications are unfortunately reasonably common following ALT pedicled flap phalloplasty, including both fistulas (often at the junction between the phallic urethra and the pars fixa of the female urethra) and strictures. Overall, rates of fistulae and strictures approximate $22 \%$ and $7 \%$ respectively $(3,62)$.

Surgical repair of fistulae is not always mandatory; spontaneous resolution was reported in $35.7 \%$ of cases within 2 months by Nikolavsky et al. in 2007 (63). On the other hand, strictures, commonly required revision surgery and re-urethroplasty.

\section{LDF (MLD)}

The MLD free flap has demonstrated favourable results in TPC. MLD has a reliable and suitable anatomy to fulfil both aesthetic and functional goals of phalloplasty (64).

Acceptable and concealable donor site scar, adequate length of the neurovascular bundle, large available flap donor area and the final aesthetic genital appearance and functional results (sexual intercourse and standing micturition) are among the main advantages of MLD $(37,64,65)$. However, downsides of the MLD flap include a potentially bulky phallus and the lack of sensitivity $(<20 \%$ of cases reported tactile sensation) (66). MLD flap blood supply relies on the thoracodorsal artery and veins and is innervated by the thoracodorsal motor nerve $(65,66)$.

As for the other TPC techniques, following neophallus creation, additional stages include glans sculpture, lengthening or joining-up urethroplasty and PPI. These manoeuvres should be performed, according to patient's requests, some months (4-6 in general) following the primary procedure.

To report that the glans can either be included in the main procedure design through a distal $5 \mathrm{~cm}$ area and a $1 \mathrm{~cm}$ de-epithelialised skin strip which recreate respectively the glans and the coronal sulcus (65).

\section{Surgical steps and outcomes}

Prior to surgery, some authors recommend massage treatment to the donor, non-dominant site, for at least 3 months, to improve skin elasticity and allow direct closure $(38,66)$. In obese patients, the donor area may be treated with liposuction to improve final graft appearance (65). The patient is placed in an upper torso full lateral position at $90^{\circ}$ while the pelvis is rotated by $30^{\circ}$, to allow the surgeon access to the recipient site and blood vessels (38). Anterior and superior muscle edges and the thoracodorsal pedicle skin-projection are marked. MLD flap size is shaped according to general adult population penile measures (11-15 cm wide and 13-18 cm long) (65-67).

On the anterior side of the flap, the dissection is 
conducted down to the deep fascia developing the plane between latissimus dorsi and anterior serratus muscles. All of the large posterior branches of the intercostal vessels are ligated and divided and MLD neurovascular pedicle is progressively isolated up to the axillary vessels. Once the flap is completely isolated, before neurovascular pedicle transection, the muscle layer of latissimus dorsi is fixed to the skin to prevent layer separation during the following steps and the flap is finally tubularised (68).

The tubularised MLD flap is then detached from the axillary region and the donor site is closed directly by approximating its edges or in some cases with additional skin grafting. The phallus is transferred to the mons pubis, already prepared with a Y-shaped incision, where it is fixed. The flaps vascular pedicle is passed through a subcutaneous tunnel to the thigh and microsurgical anastomoses are performed between the thoracodorsal and femoral arteries (end to side) and thoracodorsal and saphenous veins (end to end). Alternatively, the deep inferior epigastric artery and vein can be used for vascular connections. The thoracodorsal nerve is coapted with ilioinguinal or obturator nerves (65-67).

Postoperatively, a purpose designed dressing that keeps the neophallus elevated is recommended, predominantly to prevent pedicle kinking for the first 7-10 days. Flap viability is evaluated by clinical examination (skin colour, local temperature, capillary refill and through pocket doppler device scan) $(37,65,66)$. Vessely recommended postoperative electrostimulation of the motor nerve at least 3 times a week for at least 6 months. Electrogymnastics is useful for gaining satisfactory voluntary movement of the flap muscle (67). Ranno et al. reported that $82 \%$ of cases were able to efficiently contract the muscle after a mean follow-up of 4 months even if it is unpractical for penetrative intercourse (68).

Urethral reconstruction begins from the pars-fixa. Well vascularised periurethral skin flaps from labia minora, dorsal clitoral skin and anterior vaginal wall are mobilised, joined to the original urethral plate and tubularised over a $14 \mathrm{~F}$ catheter. Subcutaneous tissues and Martius' flaps are employed used to strengthen the neourethral wall while the labia majora are joined in the midline to create the scrotum (66). The reconstruction of the distal neourethra usually follows staged procedures. A full-thickness skin graft using a hairless region of the medial arm or buccal mucosa graft can be used in a staged Johansen type procedure. Following a ventral incision, adequate space for the graft is prepared. Skin or buccal grafts are quilted down to prevent movement and graft loss. Some months later, the lateral edges of the neo-urethral plate are incised and tubularised on a 14-16F; this can then be anatomised to the proximal urethra $(37,66)$.

The clitoris is de-epithelialised, detached from the pubic bone and fixed at the base of the neophallus. After urethral construction a suprapubic catheter is used to drain the bladder. After 3 weeks, urethral healing and absence of urethro-cutaneous fistula are confirmed with voiding urethrography.

From a cosmesis perspective, the majority of patients $(94-100 \%)$ are satisfied with the their male genitalia after MLD $(46,66)$. In one study, all patients reported erogenous sensation and orgasms based on clitoral stimulation (66). Adequate urinary function in standing position has been described in all patients (3).

Vascular thrombosis have been fortunately uncommon at $3.8 \%$, while more common MLD complications include fistula formation (13-34\%), urethral stricture $(40 \%)$, haematoma $(13-23 \%)$ and excessive swelling of the neophallus $(6-11 \%)(3,66-68)$. Urethral and vascular complications in the majority of cases $(75 \%)$ required revision surgery (66).

\section{FOFF}

FOFF is alternative option for TPR. From 1993, Sadove et al. started using FOFF for phalloplasty relying on the intrinsic rigidity of the flap (based on an autologous bone transfer) and its superior length of the vascular pedicle (37,69-72).

FOFF is based on the peroneal artery and vein and their perforating vessels. The flap fibular bone component affords phallic rigidity without the need of penile prosthesis. However, Colebunders et al. reported that the persistent erection of the flap and a pointed distal part deformity could generate discomfort and complaints $(40,58)$.

Since the skin of the fibular flap is somewhat stiff and not free to be rolled on itself to create the neourethra, some authors have proposed to prelaminate the neourethra with STSG 6 months prior to the FOFF (71-74). Donor site scarring is much reduced compared to other flap options, and can be easily covered by a sock or long trousers (75).

\section{Surgical steps and outcomes}

During the preoperative evaluation, a doppler ultrasound scan is used to identify any anatomical vascular variations. Strauch reported that in up to $8 \%$ of cases the peroneal artery takes the place of the posterior tibial artery and therefore, if FOFF is harvested, the blood supply of the leg 
could be compromised. In case of doubt, angiography is a second level investigational option (76).

As described previously, 6 months prior to FOFF harvesting, the donor-site is prelaminated to create the neourethra. A tunnel is bluntly dissected in the donor leg.

A hairless skin flap, either from the inner aspect of the upper arm or chest wall or proximal thigh $(71,72,74)$, is harvested. The skin flap is then rolled over a catheter and the neourethra is transferred to the suprafascial tunnel on the lateral aspect of the leg. Afterwards, the fibula, together with its neurovascular components (artery with septocutaneous perforators and lateral sural cutaneous nerve (LSCN) as well as the overlying skin), are marked out (69-71). The surgical incision is deepened up to the subfascial layer and the posterior intermuscular septum is dissected, without damaging the septocutaneous branches. A fibular osteotomy is performed leaving in situ some amount of bone to guarantee joint stability $(69,70)$. Hage et al. have suggested to harvest a bone segment $2 \mathrm{~cm}$ longer than FOFF to improve proximal fixation to pubic bone and consequent phallus rigidity (72). The vascular pedicle (fibular artery and vein) can thereafter be identified and dissected up to its origin from the posterior tibial artery and vein. Once harvested, the flap is rolled up to cover the fibula in a tension free manner. The flap is moved to the pubic area where it is fixed to the pubic periosteum and flap vessels are microsurgically anastomosed to the recipient femoral artery and saphenous vein. Similarly, the LSCN is coapted to one dorsal nerves of the clitoris. Since LSCN and clitoral nerves coaption often results in poor erogenous phallic sensation, it is highly suggested that the contralateral clitoral nerve should be preserved $(70-72,75)$. The donor site is covered by full-thickness skin graft (74).

Approximately 2-3 months after the main procedure, an end-to-end anastomosis between the prelaminated neourethra and the native urethra is performed $(71,74)$. The vast majority of patients seem satisfied with the overall result of their TPR. Ninety percent of patients report adequate urinary function while standing and successful penetrative intercourse in $52 \%$ of cases after FOFF (3). Although FOFF is a microsurgical free flap procedure, probably due to the long available vascular pedicle and direct anastomoses with large caliber recipient vessels, vascular complications have infrequently occurred. Overall complete loss and partial flap loss or distal necrosis are respectively reported in $1.5 \%$ and $11.9 \%$ of cases with a need of vascular surgical revision rate of $18.7 \%(37,71)$. Infection and wound healing issues are reported in $6.2 \%$ and $12.5 \%$ of patients (71). Donor- site morbidity from fibula grafting is minimal, although published reports are limited. All patients report alterated cutaneous sensation of the lateral aspect of the leg and foot due to the harvesting of $\operatorname{LSCN}(71,74,76)$, which is a unique complication for this option of phalloplasty flap.

Similar to other TPR techniques, FOFF is frequently plagued by urinary complications. Before urethral prelamination, urethral strictures and fistulas occurred in up to $80 \%$ of cases, while now urethral fistula is reported in $9.6 \%$ and urethral stricture in $17 \%$ of cases $(37,71,74)$. Although FOFF provides additional length and girth potential as well as inherent rigidity compared to RAFFF, phallus sensitivity is lower in case of FOFF even though many describe acceptable tactile and erogenous sensation $(71,72,77,78)$.

\section{GF}

The GF was more commonly used prior to the development of microsurgical techniques. GF are pedicled and generally based on the iliac vessels. A lateral groin flap comprises thin hairless skin, which has an appearance similar to genital area skin. GF may therefore have a cosmetic advantage compared to free flaps. Donor site scarring can also be minimized as the area is easily concealable $(79,80)$. On the other hand, reduced sensitivity, issues concerning micturition in standing position and penetrative intercourses are the main drawbacks of GF and they are similar to those of the abdominally pedicled flaps $(80,81)$. Furthermore, donor-site morbidity after GF is not uncommon, changes in sensation of the thigh and hernias have been reported.

\section{Surgical steps and outcomes}

In the preoperative setting a doppler ultrasound is used to outline the course of the superficial iliac circumflex artery (SICA) and in some cases deep iliac circumflex artery (DICA), which are marked up on the skin.

The SICA needs to extend beyond the anterosuperior iliac spine by at least $3-4 \mathrm{~cm}$, if this condition is respected the donor area is designed including the iliac crest bone in its entire length. Some authors have proposed the use of a vascularised iliac bone flap for phallus rigidity. In this case, in addition to the SICA, it is necessary to isolate and include the DICA to ensure vascular support to the bone component (79-81). The flap pedicle is gently dissected up to the SICA origin from the femoral artery and the flap is harvested following the deep fascia layer reaching 
the preperitoneal fat. An inguinal subcutaneous tunnel is created between the donor-site and the pubic area. The flap is transferred and tubularised. The procedure could be performed in one or two steps, likewise other abdominal flaps, and a skin-graft prefabricated urethra can be placed within the flap before its transfer $(3,81,82)$. The distal part of the GF is shaped and closed while in case of prefabricated urethra, the anastomosis between the neourethra and the pars fixa is carried out with local labial flaps. Erogenous sensation of the neophallus is provided by the preserved clitoris, positioned at the base of the phallic shaft (81).

Data on complications and surgical outcomes of GF are very limited. As with all flaps, vascular complications are the most feared and distal necrosis is reported up to $16 \%$ while total flap loss in $3 \%$ of cases. Urethral fistula is reported in $5.5 \%$ of patients. When reported, functional and satisfaction outcomes were adequate $(3,80)$.

\section{Clitoris management}

Regardless of the TPC technique used, the surgical steps observed by the different surgical teams, it emerged, from literature, that the preservation of the clitoris and its innervation is mandatory. During the first surgical step, especially in the case of free-flaps TPC, clitoris is generally not included, at the same time, in the phallus. During the first surgical step, sensitive nerves from the flap could be coapted to one clitoral nerve in order to provide the neophallus with erogenous sensitivity (that will appear over the following months). During anatomical dissection and clitoral isolation, it is also essential not to damage both clitoral nerves in order to preserve the erogenous sensitivity and the ability to reach orgasm after TPC. Usually in the second surgical step, during join-up urethroplasty, vaginectomy and scrotoplasty, the clitoris is then moved and hidden at the base of the neo phallus. Despite clitoral mobilization, de-epithelization and distal mucosectomy, the clitoris maintains its function to transfer erogenous stimuli and thus allow the achievement of orgasm. Incorrect management of the clitoris could compromise functional results and patient satisfaction and therefore it is essential that maximum attention is paid to the clitoris and to the preservation of its function during the GGAS.

\section{Discussion}

TPR is a challenging and demanding procedure, with significant advances over the years to improve functional and aesthetic outcomes. Voiding while standing ability and an aesthetically appealing appearance of the neophallus are some of the top priorities in female to male confirming surgery (83).

Since smoking has been shown to increase the risk of vascular complications in microsurgical free-flap procedures, some authors advise to cease smoking some weeks/months before the procedure; there is no consensus concerning the ideal time to quit prior to surgery (84). Androgenic and testosterone-based therapies may increase thrombotic risk and should be discontinued at least 2 weeks before surgery. Finally, laser-based hair removal should be considered to minimise neo-urethral complications if the ulnar aspect of the forearm is particularly hairy.

The different procedures described can be distinguished into free-flaps (MLD, RAFFF and FOFF) and pedicled flaps (SPP, ALT and GF). All free-flap procedures have their relative disadvantage, such as donor site (e.g., forearm scarring in RAFFF) that could be considered a stigmata by patients (78). On the other hand, free-flaps have some advantages derived fromt their improved aesthetic result compared to the wedge shaped neophallus obtained with pedicled abdominal or groin flaps (85).

Given the absence of randomised controlled or comparative trials between the different surgical techniques and the lack of validated tools to analyse postoperative outcomes and complications, it is currently difficult to draw definitive conclusions on the best TPR technique. The different techniques meet the various needs of individual patients. Recently the demand for TPR seems to be on the rise $(86,87)$; this trend could be an opportunity to coordinate larger-scale controlled prospective studies.

\section{Conclusions}

TPR is an evolving area aimed at improving the aesthetic and functional results of the neophallus. Whilst the true ideal neophallus does not yet exist, our efforts must be aimed at improving patient outcomes, whilst limiting the invasiveness, number of procedures and surgical complications.

\section{Acknowledgments}

Funding: None.

\section{Footnote}

Provenance and Peer Review: This article was commissioned 
by the Guest Editors (Francisco E. Martins and Tobias S. Köhler) for the series "Controversies and Considerations of Penile Surgery" published in Translational Andrology and Urology. The article has undergone external peer review.

Reporting Checklist: The authors have completed the PRISMA reporting checklist. Available at http://dx.doi. org/10.21037/tau-20-1340

Conflicts of Interest: The authors have completed the ICMJE uniform disclosure form (available at http://dx.doi. org/10.21037/tau-20-1340). The series "Controversies and Considerations of Penile Surgery" was commissioned by the editorial office without any funding or sponsorship. The authors have no other conflicts of interest to declare.

Ethical Statement: The authors are accountable for all aspects of the work in ensuring that questions related to the accuracy or integrity of any part of the work are appropriately investigated and resolved.

Open Access Statement: This is an Open Access article distributed in accordance with the Creative Commons Attribution-NonCommercial-NoDerivs 4.0 International License (CC BY-NC-ND 4.0), which permits the noncommercial replication and distribution of the article with the strict proviso that no changes or edits are made and the original work is properly cited (including links to both the formal publication through the relevant DOI and the license). See: https://creativecommons.org/licenses/by-nc-nd/4.0/.

\section{References}

1. Selvaggi G, Dhejne C, Landen M, et al. The 2011 WPATH Standards of Care and Penile Reconstruction in Female-to-Male Transsexual Individuals. Adv Urol 2012;2012:581712.

2. Monstrey S, Hoebeke P, Selvaggi G, et al. Penile reconstruction: Is the radial forearm flap really the standard technique? Plast Reconstr Surg 2009;124:510-8.

3. Morrison SD, Shakir A, Vyas KS, et al. Phalloplasty: A Review of Techniques and Outcomes. Plast Reconstr Surg 2016;138:594-615.

4. Hage JJ, Bouman FG, de Graaf FH, et al. Construction of the neophallus in fe-male-to-male transsexuals: The Amsterdam experience. J Urol 1993;149:1463-8.

5. Hage JJ, Bloem JJ. Review of the literature on construction of a neourethra in female-to-male transsexuals. Ann Plast
Surg 1993;30:278-86.

6. Song C, Wong M, Wong C, et al. Modifications of the Radial Forearm Flap Phalloplasty for Female-toMale Gender Reassignment. J Reconstr Microsurg 2011;27:115-20.

7. Rashid M, Tamimy MS. Phalloplasty: The dream and the reality. Indian J Plast Surg 2013;46:283-93.

8. Sarıkaya S, Ralph DJ. Mystery and realities of phalloplasty: a systematic review. Turk J Urol 2017;43:229-36.

9. Rieger UM, Majenka P, Wirthmann A, et al. Comparative Study of the Free Mi-crovascular Groin Flap: Optimizing the Donor Site After Free Radial Forearm Flap Phalloplasty. Urology 2016;95:192-6.

10. Salgado CJ, Chim H, Tang JC, et al. Penile reconstruction. Semin Plast Surg 2011;25:221-8.

11. Selvaggi G, Elander A. Penile reconstruction/formation. Curr Opin Urol 2008;18:589-97.

12. Selvaggi G, Bellringer J. Gender reassignment surgery: An overview. Nat Rev Urol 2011;8:274-82.

13. Morrison SD, Perez MG, Nedelman M, et al. Current state of female-to-male gender confirming surgery. Curr Sex Health Rep 2015;7:38-48.

14. Monstrey SJ, Ceulemans P, Hoebeke P. Sex reassignment surgery in the fe-male-to-male transsexual. Semin Plast Surg 2011;25:229-44.

15. Selvaggi G, Branemark R, Elander A, et al. Titaniumbone-anchored penile ep-ithesis: Preoperative planning and immediate postoperative results. J Plast Surg Hand Surg 2015;49:40-4.

16. Doornaert M, Hoebeke P, Ceulemans P, et al. Penile reconstruction with the radial forearm flap: an update. Handchir Mikrochir Plast Chir 2011;43:208-14.

17. Garaffa G, Christopher NA, Ralph DJ. Total phallic reconstruction in female-to-male transsexuals. Eur Urol 2010;57:715-22.

18. Moher D, Shamseer L, Clarke M, et al. Preferred reporting items for systematic review and meta-analysis protocols (PRISMA-P) 2015 statement. Syst Rev 2015;4:1.

19. Kim SK, Lee KC, Kwon YS, et al. Phalloplasty using radial forearm osteocu-taneous free flaps in femaleto-male transsexuals. J Plast Reconstr Aesthet Surg 2009;62:309-17.

20. Ma S, Cheng K, Liu Y. Sensibility following innervated free radial forearm flap for penile reconstruction. Plast Reconstr Surg 2011;127:235-41.

21. Ramesh S, Serjius A, Wong TB, et al. Two stage penile reconstruction with free prefabricated sensate radial forearm osteocutaneous flap. Med J Malaysia 
2008;63:343-5.

22. Van Caenegem E, Verhaeghe E, Taes Y, et al. Longterm evaluation of donor-site morbidity after radial forearm flap phalloplasty for transsexual men. J Sex Med 2013;10:1644-51.

23. Monstrey S, Hoebeke P, Dont M, et al. Radial forearm phalloplasty: A review of 81 cases. Eur J Plast Surg 2005;28:206-12.

24. Wirthmann, AE. Majenka P, Kaufmann MC, et al. Phalloplasty in Female-to-Male Transsexuals by Gottlieb and Levine's Free Radial Forearm Flap Technique-A Long-Term Single-Center Experience Over More than Two Decades. J Reconstr Microsurg 2018;34:235-41.

25. Selvaggi G, Monstrey S, Hoebeke P, et al. Donorsite morbidity of the radial forearm free flap after 125 phalloplasties in gender identity disorder. Plast Reconstr Surg 2006;118:1171-7.

26. Chang TS, HwangWY. Forearm flap in one-stage reconstruction of the penis. Plast Reconstr Surg 1984;74:251-8.

27. Gottlieb LJ, Levine LA. A new design for the radial forearm freeflap phallic construction. Plast Reconstr Surg 1993;92:276-83, discussion 284.

28. Kovar A, Choi S, Iorio ML. Donor Site Morbidity in Phalloplasty Reconstruc-tions: Outcomes of the Radial Forearm Free Flap. Plast Reconstr Surg Glob Open 2019;7:e2442.

29. Blaschke E, Bales GT, Thomas S. Postoperative imaging of phalloplasties and their complications. AJR Am J Roentgenol 2014;203:323-8.

30. Müller-Richter UD, Driemel O, Mörtl M, et al. The value of Allen's test in har-vesting a radial forearm flap: correlation of ex-vivo angiography and histopatholog-ical findings. Int J Oral Maxillofac Surg 2008;37:672-4.

31. De Cuypere G, T'Sjoen G, Beerten R, et al. Sexual and phys- ical health after sex reassignment surgery. Arch Sex Behav 2005;34:679-90.

32. Selvaggi G, Monstrey S, Ceulemans P, et al. Genital sensitivity after sex reas- signment surgery in transsexual patients. Ann Plast Surg 2007;58:427-33. Pub-Med

33. McRoberts JW, Sadove RC. Penile reconstruction with a free sensate osteocu-taneous fibula flap in the surgical management of the intersex patient. Adv Exp Med Biol 2002;511:283-7; discussion 287.

34. Hage JJ, de Graaf FH, Bouman FG, et al. Sculpturing the glans in phalloplasty. Plast Reconstr Surg 1993;92:157-61.

35. Hage JJ, Bouman FG, Bloem JJ. Construction of the fixed part of the ne-ourethra in female-to-male transsexuals:
Experience in 53 patients. Plast Reconstr Surg 1993;91:904-10; discussion 911-3.

36. Rohrmann D, Jakse G. Urethroplasty in female-to-male transsexuals. Eur Urol 2003;44:611-4.

37. Yao A, Ingargiola MJ, Lopez CD, et al. Total penile reconstruction: A system-atic review. J Plast Reconstr Aesthet Surg 2018;71:788-806.

38. Djordjevic ML. Novel surgical techniques in female to male gender confirming surgery. Transl Androl Urol 2018;7:628-38.

39. van der Sluis WB, Smit JM, Pigot GLS, et al. Double flap phalloplasty in transgender men: Surgical technique and outcome of pedicled anterolateral thigh flap phalloplasty combined with radial forearm free flap urethral reconstruction. Microsurgery 2017;37:917-23.

40. Terrell M, Roberts W, Price CW, et al. Anatomy of the pedicled anterolateral thigh flap for phalloplasty in transitioning-males. Clin Anat 2018;31:160-8. Pub-Med

41. De Wolf E, Claes K, Sommeling CE, et al. Free Bipedicled Radial Forearm and Posterior Interosseous Artery Perforator Flap Phalloplasty. J Sex Med 2019;16:1111-7.

42. Wirthmann A, Finke JC, Giovanoli P, et al. Long-term follow-up of donor site morbidity after defect coverage with Integra following radial forearm flap elevation. Eur J Plast Surg 2014;37:159-66.

43. Ascha M, Massie JP, Morrison SD, et al. Outcomes of Single Stage Phalloplas-ty by Pedicled Anterolateral Thigh Flap versus Radial Forearm Free Flap in Gender Confirming Surgery. J Urol 2018;199:206-14.

44. Lumen N, Monstrey S, Goessaert AS, et al. Urethroplasty for strictures after phallic reconstruction: a singleinstitution experience. Eur Urol 2011;60:150-8.

45. Garaffa G, Ralph DJ, Christopher N. Total urethral construction with the radial artery-based forearm free flap in the transsexual. BJU Int 2010;106:1206-10. Pub-Med

46. Leriche A, Timsit MO, Morel-Journel N, et al. Long-term outcome of forearm flee-flap phalloplasty in the treatment of transsexualism. BJU Int 2008;101:1297-300.

47. Falcone M, Timpano M, Oderda M, et al. Suprapubic pedicled phallo-plasty in transgender men: a multicentric retrospective cohort analysis. Int J Impot Res 2020;10.1038 s41443-020-0238-4.

48. Bogoraz N. Plastic construction of penis capable of accomplishing coitus. Zen-tral Chir 1936;63:1271-6.

49. Maltz M. Maltz reparative technique for the penis. In: Maltz M. editor. Evolu-tion of Plastic Surgery. New York, NY: Froben Press, 1946:278-9.</edb>

50. Gillies H, Harrisson RJ. Congenital absence of the penis. 
Br J Plast Surg 1948;1:8-28.

51. Seyhan T, Borman H. Pedicled deep inferior epigastric perforator flap for low-er abdominal defects and genital reconstructive surgery. J Reconstr Microsurg 2008;24:405-12.

52. Davies DM, Matti BA. A method of phalloplasty using the deep inferior epi-gastric flap. Br J Plast Surg 1988;41:165-8.

53. Bettocchi C, Ralph DJ, Pryor JP. Pedicled pubic phalloplasty in females with gender dysphoria. BJU Int 2005;95:120-4.

54. Terrier JÉ, Courtois F, Ruffion A, et al. Surgical outcomes and patients' satis-faction with suprapubic phalloplasty. J Sex Med 2014;11:288-98.

55. Zhang Y, Lu L, Zhang W, et al. A simple and effective method for phalloplas-ty in female-to-male transsexuals. Plast Reconstr Surg 2010;126:264e-265e. Pub-Med

56. Lee GK, Lim AF, Bird ET. A novel single-flap technique for total penile re-construction: the pedicled anterolateral thigh flap. Plast Reconstr Surg 2009;124:163-6.

57. Felici N, Felici A. A new phalloplasty technique: the free anterolateral thigh flap phalloplasty. J Plast Reconstr Aesthet Surg 2006;59:153-7.

58. Colebunders B, Brondeel S, D'Arpa S, et al. An Update on the Surgical Treat-ment for Transgender Patients. Sex Med Rev 2017;5:103-9.

59. Wei FC, Jain V, Celik N, et al. Have we found an ideal soft tissue flap? An experience with 672 anterolateral thigh flaps Plast Reconstr Surg 2002;109:2219-26.

60. Morrison SD, Son J, Song J, et al. Modification of the tube- in-tube pedicled anterolateral thigh flap for total phallo- plasty: The mushroom flap. Ann Plast Surg 2014;72:S22-6.

61. D'Arpa S, Claes K, Lumen N, et al. Urethral Reconstruction in Anterolateral Thigh Flap Phalloplasty: A 93-Case Experience. Plast Reconstr Surg 2019;143:382e-92e.

62. Xu KY, Watt AJ. The Pedicled Anterolateral Thigh Phalloplasty. Clin Plast Surg 2018;45:399-406.

63. Nikolavsky D, Yamaguchi Y, Levine JP, et al. Urologic Sequelae Following Phalloplasty in Transgendered Patients. Urol Clin North Am 2017;44:113-25. Pub-Med

64. Dennis M, Granger A, Ortiz A, et al. The anatomy of the musculocutaneous latissimus dorsi flap for neophalloplasty. Clin Anat 2018;31:152-9.

65. Perovic SV, Djinovic R, Bumbasirevic M, et al. Total phalloplasty using a mus-culocutaneous latissimus dorsi flap. BJU Int 2007;100:899-905.
66. Djordjevic ML, Bencic M, Kojovic V, et al. Musculocutaneous latissimus dorsi flap for phalloplasty in female to male gender affirmation surgery. World J Urol 2019;37:631-7.

67. Vesely J, Hyza P, Ranno R, et al. New technique of total phalloplasty with reinnervated latissimus dorsi myocutaneous free flap in female-to-male transsexuals. Ann Plast Surg 2007;58:544-50.

68. Ranno R, Vesely J, Hyza P, et al. Neo-phalloplasty with reinnervated latissi-mus dorsi free flap: a functional study of a novel technique. Acta Chir Plast 2007;49:3-7.

69. Sadove RC, McRoberts JW. Total phallic reconstruction with the free fibula osteocutaneous flap. Plast Reconstr Surg 1992;89:1001.

70. Sadove RC, Sengezer M, McRoberts JW, et al. Onestage total penile recon-struction with a free fibula osteocutaneous flap. Plast Reconstr Surg 1993;92:1314-23.

71. Papadopulos NA, Schaff J, Biemer E. The use of free prelaminated and sensate osteofasciocutaneous fibular flap in phalloplasty. Injury 2008;39 Suppl 3:S62-7.

72. Hage JJ, Winters HA, Van Lieshout J. Fibula free flap phallo- plasty: modifica-tions and recommendations. Microsurgery 1996;17:358-65.

73. Chen HC, Gedebou TM, Yazar S, et al. Prefabrication of the free fibula oste-ocutaneous flap to create a functional human penis using a controlled fistula meth-od. J Reconstr Microsurg 2007;23:151-4.

74. Dabernig J, Chan LK, Schaff J. Phalloplasty with free (septocutaneous) fibular flap sine fibula. J Urol 2006;176:2085-8.

75. Zaheer U, Granger A, Ortiz A, et al. The anatomy of free fibula osteoseptocu-taneous flap in neophalloplasty in transgender surgery. Clin Anat 2018;31:169-74.

76. Pototschnig H, Schaff J, Kovacs L, et al. The free osteofasciocutaneous fibula flap: clinical applications and surgical considerations. Injury 2013;44:366-9.

77. Schaff J, Papadopulos NA. A new protocol for complete phalloplasty with free sensate and prelaminated osteofasciocutaneous flaps: experience in 37 patients. Microsurgery 2009;29:413-9.

78. Kropp B, Cohn JE, Wang W, et al. Free Tissue Transfer Penile Reconstruction. Semin Plast Surg 2019;33:24-9.

79. Sun GC, Huang JJ. One-stage reconstruction of the penis with composite iliac crest and lateral groin skin flap. Ann Plast Surg 1985;15:519-28.

80. Zieliński T. Phalloplasty using a lateral groin flap in female- to-male transsexu-als. Acta Chir Plast 1999;41:15-9. 
81. Aköz T, Kargi E. Phalloplasty in a female-to-male transsexual using a double-pedicle composite groin flap. Ann Plast Surg 2002;48:423-7.

82. Puckett CL, Montie JE. Construction of male genitalia in the transsexual, using a tubed groin flap for the penis and a hydraulic inflation device. Plast Reconstr Surg 1978;61:523-30.

83. Hage JJ, Bout CA, Bloem JJ, et al. Phalloplasty in femaletomale transsexuals: what do our patients ask for? Ann Plast Surg 1993;30:323-6.

84. Chang LD, Buncke G, Slezak S, et al. Cigarette smoking,

Cite this article as: Falcone M, Preto M, Blecher G, Timpano M, Gontero P. Total phallic construction techniques in transgender men: an updated narrative review. Transl Androl Urol 2021;10(6):2583-2595. doi: 10.21037/tau-20-1340 plastic surgery, and microsurgery. J Reconstr Microsurg 1996;12:467-74.

85. Puckett CL, Reinisch JF, Montie JE. Free flap phalloplasty. J Urol 1982;128:294-7.

86. Aydin D, Buk LJ, Partoft S, et al. Trans- gender Surgery in Denmark From 1994 to 2015: 20-Year Follow- Up Study. J Sex Med 2016;13:720-5.

87. Majumder A, Sanyal D. Outcome and preferences in female-to- male subjects with gender dysphoria: Experience from Eastern India. Indian J Endocrinol Metab 2016;20:308-11. 